\title{
Patients' and urologists' preferences for prostate cancer treatment: a discrete choice experiment
}

\author{
E W de Bekker-Grob*, ${ }^{*}$, M C J Bliemer ${ }^{2}$, B Donkers ${ }^{3}$, M-L Essink-Bot ${ }^{4}$, I J Korfage ${ }^{1}$, M J Roobol ${ }^{5}, \mathrm{C} \mathrm{H} \mathrm{Bangma}^{5}$ \\ and E W Steyerberg ${ }^{1}$ \\ ${ }^{1}$ Department of Public Health, Erasmus MC-University Medical Centre Rotterdam, PO Box 2040, Rotterdam, The Netherlands; \\ ${ }^{2}$ Institute of Transport and Logistics Studies, University of Sydney, Sydney, New South Wales, Australia; ${ }^{3}$ Department of Business \\ Economics, Erasmus University Rotterdam, Rotterdam, The Netherlands; ${ }^{4}$ Department of Public Health, Academic Medical Centre, \\ University of Amsterdam, Amsterdam, The Netherlands and ${ }^{5}$ Department of Urology, Erasmus MC_-University Medical Centre \\ Rotterdam, Rotterdam, The Netherlands
}

Background: Patients' preferences are important for shared decision making. Therefore, we investigated patients' and urologists' preferences for treatment alternatives for early prostate cancer (PC).

Methods: A discrete choice experiment was conducted among 150 patients who were waiting for their biopsy results, and 150 urologists. Regression analysis was used to determine patients' and urologists' stated preferences using scenarios based on PC treatment modality (radiotherapy, surgery, and active surveillance (AS)), and risks of urinary incontinence and erectile dysfunction.

Results: The response rate was 110 out of 150 (73\%) for patients and 50 out of 150 (33\%) for urologists. Risk of urinary incontinence was an important determinant of both patients' and urologists' stated preferences for $\mathrm{PC}$ treatment $(P<0.05)$. Treatment modality also influenced patients' stated preferences $(P<0.05)$, whereas the risk of erectile dysfunction due to radiotherapy was mainly important to urologists $(P<0.05)$. Both patients and urologists preferred AS to radical treatment, with the exception of patients with anxious/depressed feelings who preferred radical treatment to AS.

Conclusion: Although patients and urologists generally may prefer similar treatments for PC, they showed different trade-offs between various specific treatment aspects. This implies that urologists need to be aware of potential differences compared with the patient's perspective on treatment decisions in shared decision making on PC treatment.

The introduction of prostate specific antigen (PSA) assays in the early 1990s dramatically improved the diagnostic capability to detect prostate cancer (PC) at an early stage (i.e., early PC; Gillitzer and Thuroff, 2003). Several treatments exist for early PC, some of which (e.g. surgery and radiotherapy) may cause bowel problems, incontinence, erectile dysfunction, and other complications. However, in case of low-risk tumours, active surveillance (AS) may result in a mortality rate similar to these radical treatments (Klotz, 2006). Although AS may avoid the risk of the side effects associated with radical treatment, anxiety and distress may increase because patients know that they have to live with the idea of having PC that is not radically treated (van den Bergh et al, 2010).

In an era of shared decision making, clinicians must ensure that their patients experience minimal post-treatment decisional regret (Aning et al, 2012). The evidence to date suggests that patients' views and beliefs and those of their physician may not always be in agreement (Emberton, 2010). This phenomenon is also seen among urologists and their patients. For example, in the context of benign prostate hyperplasia, patients with this disorder had (very) different expectations of treatment compared with that of their 
urologists (Kim et al, 2011). Similarly, in the context of PC treatment, studies show that urologists had considerable influence on the choice of PC treatment, and that the treatment choice of the patient was influenced by the hospital they visited (van Tol-Geerdink et al, 2013). Differences in opinion on the desirability of a specific treatment may hamper the communication process and the outcome of shared decision making between the urologist and patient (Montgomery and Fahey, 2001). To ensure that patients with early PC experience minimal post-treatment decisional regret, insight into patients' and urologists' preferences for PC treatment is needed. However, (quantitative) studies investigating and comparing patients' and urologists' (stated) preferences for PC treatment alternatives are lacking.

Therefore, we aimed to investigate and compare the stated preferences of patients and urologists for treatment for early PC. For this, we used a discrete choice experiment (DCE). DCEs are a quantitative approach to assess preferences for medical interventions, products, or policies and have been employed across a number of discipline areas, including marketing, environmental, and transport economics, and are increasingly used in health care (de Bekker-Grob et al, 2012; see 'Discrete choice experiment' section for more details).

\section{MATERIALS AND METHODS}

Study samples and elicitation mode. During January-November 2011, we prospectively approached 150 patients from Erasmus University Medical Centre (Rotterdam, the Netherlands) who participated in the Dutch part of the European Randomized Study of Screening for Prostate Cancer (ERSPC; Schroder et al, 2012). The ERSPC is a multicentre trial initiated in 1991 in the Netherlands and in Belgium, with five additional European countries (Sweden, Finland, Italy, Spain, and Switzerland) joining between 1994 and 1998 (see Roobol and Schroder (2003) and Schroder et al (2009) for the trial protocol).

We invited patients who had undergone a prostate biopsy after a positive PSA test result, but who had not yet received their biopsy result. The rationale for this was to allow to investigate the stated preferences of patients for whom choosing between PC treatments in real life might be (very) realistic, and to compare their stated preferences with actual behaviour. This is an additional strength of the present study, as external validity tests of DCE outcomes in health care are limited (de Bekker-Grob et al, 2012).

Patients were contacted personally by a health professional on the day they underwent prostate biopsy, that is, they had knowledge of their abnormal PSA result but did not know the biopsy result. They received a paper copy of the survey comprising DCE questions, and an information letter with general and background information about PC and PC treatment.

The second study group consisted of 150 urologists throughout the Netherlands (all members of the Dutch Association of Urology) who received a paper copy of the survey comprising DCE questions by mail. Urologists who mentioned that they had no experience in PC treatment, or were specialised in children care, were excluded from the study. All participants (patients and urologists) could return the questionnaire in a postage-paid envelope that was included in the (mailing) package. In the present study, the participation of patients and urologists was completely voluntary; no incentives were used.

Approval for the study was obtained from the Medical Ethics Committee, Erasmus MC, University Medical Centre Rotterdam (MEC-2010-316).

Discrete choice experiment. In DCEs, it is assumed that a medical intervention, such as a treatment, can be described by its characteristics (attributes; e.g. risk of side effects; Ryan, 2004).
Those characteristics are further specified by variants of that characteristic (attribute levels; e.g. for risk of side effects: 10, 20, and $30 \%)$. A second assumption is that the individual's preference for a medical intervention is determined by the levels of those attributes (Ryan, 2004). The relative importance of attributes and the trade-offs that respondents make between them can be assessed by offering a series of choices between two or more medical intervention alternatives with different combinations of attribute levels (Appendix I; Hensher et al, 2005).

Alternatives, attributes, and attribute levels. Nowadays, the most widely used treatment strategies for PC are AS, radiotherapy, and surgery; in the present study, these were considered as the treatment alternatives. The attributes and the attribute levels of these treatment alternatives were derived from the literature (Stanford et al, 2000; Potosky et al, 2004; Damber and Khatami, 2005; Korfage et al, 2005; Penson et al, 2008). In addition, we interviewed urologists and senior researchers in the field of PC treatment to determine which treatment attributes were mostly considered by patients and/or urologists in choosing a PC treatment. In the interviews, we asked them to comment on and complete the list of relevant treatment attributes/attribute levels that was created from the literature review. On the basis of these data, the following PC treatment attributes were determined: permanent risk of urinary incontinence due to treatment, permanent risk of erectile dysfunction due to treatment, risk of other permanent side effects due to treatment (e.g., mortality risk, bowel problems, frequent urge to urinate), frequency of PSA testing, and treatment aim (i.e., the chance (yes/no) to physically remove the tumour from the body). The attribute levels chosen incorporated the range of plausible early PC treatment alternative specific outcomes based on current literature to create realistic PC treatment scenarios (Table 1; Appendix I); that is, curing the disease is not the aim of AS, whereas it is for radiotherapy and surgery; or AS more frequently required PSA testing than radiotherapy or surgery; or the risk of urinary incontinence is equal to or higher for surgery compared with radiotherapy.

Study design and questionnaire. The combination of the treatment alternatives, attributes, and their levels resulted in 19 possible realistic treatment scenarios (i.e., nine different radiotherapy scenarios; nine different surgery scenarios; and one AS scenario). To construct choice sets for the patients, we generated an efficient design by maximising D-efficiency (Street et al, 2005; SAS software version 9.1, SAS Institute Inc., Cary, NC, USA). To take a possible dominant treatment alternative into account (i.e., the possibility that respondents always choose the same treatment modality, irrespective of the attribute levels of the other treatment modalities), each choice set consisted of two treatment alternatives (i.e., AS $v s$ a radiotherapy or surgery alternative; a radiotherapy alternative $v s$ a surgery alternative; or two surgery or two radiotherapy alternatives with different attribute levels; Appendix I). Patients were asked to consider both PC treatment alternatives in a choice set as realistic alternatives and to choose the alternative that was most appealing to them (i.e., the type of choice question was a forced labelled choice set containing two PC treatments). Twenty-four choice sets were constructed. We expected that presenting a patient with a large number of choice sets to complete would result in a lower response rate and/or lower response reliability (Pearmain et al, 1991; Hall et al, 2006). As such, we further blocked the design into two versions of questionnaires containing 12 choice sets each (Hensher et al, 2005). For the urologists, the same procedure was followed, except that we generated an efficient design by maximising D-efficiency using prior information on the basis of DCE outcomes of 70 patients to strive for similarly reliable outcomes with a smaller sample size (Reed Johnson et al, 2013). This procedure is a strength of the study and does not influence the comparability between urologists' 
Table 1. Attributes and alternative specific levels for prostate cancer treatment

\begin{tabular}{|c|c|}
\hline Attributes & Alternative specific levels \\
\hline \multicolumn{2}{|c|}{ Risk of urinary incontinence due to treatment (\%) } \\
\hline $\begin{array}{l}\text { Active surveillance } \\
\text { Radiotherapy } \\
\text { Surgery }\end{array}$ & $\begin{array}{c}0 \\
2-5-10 \\
10-20-30\end{array}$ \\
\hline \multicolumn{2}{|c|}{ Risk of erection problems due to treatment (\%) } \\
\hline $\begin{array}{l}\text { Active surveillance } \\
\text { Radiotherapy } \\
\text { Surgery }\end{array}$ & $\begin{array}{c}0 \\
15-25-35 \\
35-45-55\end{array}$ \\
\hline \multicolumn{2}{|c|}{ Risk of other permanent side effects due to treatment } \\
\hline $\begin{array}{l}\text { Active surveillance } \\
\text { Radiotherapy } \\
\text { Surgery }\end{array}$ & $\begin{array}{l}\text { No } \\
\text { Yes, substantial risk of bowel problems and frequent } \\
\text { urge to urinate } \\
\text { Yes, small risk of mortality within } 6 \text { weeks }\end{array}$ \\
\hline \multicolumn{2}{|l|}{ Main aim is cure } \\
\hline $\begin{array}{l}\text { Active surveillance } \\
\text { Radiotherapy } \\
\text { Surgery }\end{array}$ & $\begin{array}{l}\text { No, the tumour remains in the body } \\
\text { Yes, but the disease may return } \\
\text { Yes, but the disease may return }\end{array}$ \\
\hline \multicolumn{2}{|c|}{ Frequency of PSA testing with a risk of new biopsies } \\
\hline $\begin{array}{l}\text { Active surveillance } \\
\text { Radiotherapy } \\
\text { Surgery }\end{array}$ & $\begin{array}{l}\text { Four times in a year and at least one biopsy per year } \\
\text { Once in a year } \\
\text { Once in a year }\end{array}$ \\
\hline
\end{tabular}

and patients' stated preferences as long as the ratios between parameters are compared (parameter ratios do have a natural interpretation in terms of the relative importance of attributes, and rule out a possible difference in the scale parameter; Swait and Louviere, 1993).

Irrespective of whether the subject was a urologist or patient, each questionnaire started with a detailed description of the treatment modality, attributes, and their levels; that is, patients as well as urologists received exactly the same information about PC treatments; it contained the most relevant information about several PC treatments including several risks of permanent urinary incontinency and erectile dysfunction, the risk of other permanent side effects, for example, a fixed chance of long-term bowel problems of $5 \%$ due to radiotherapy, the main aim of the PC treatment alternative, and the frequency of PSA testing. The central focus of each questionnaire comprised the 12 choice sets. To keep the choice sets understandable for respondents, we used pictures and words alongside the specific risks of urinary incontinence and erectile dysfunction, and used the words 'substantial risk of to present the fixed chance for long-term bowel problems (5\%) and frequent urge to urinate. An extra choice set was included that presented all three treatment alternatives (AS, radiotherapy, and surgery) containing the most plausible attribute levels (Appendix II). The questionnaire also contained questions on background variables and a question assessing experienced difficulty of the DCE questions. The questionnaire for the patients also included a question on generic health status (EQ-5D; including questions about mobility, self-care, usual activity, pain, and anxiety/ depression; Dolan, 1997). (The complete questionnaire and details on the DCE design are available from the authors on request).
The questionnaire was pilot tested $(n=11)$ to check for any problems in interpretation and face validity; that is, using think aloud techniques and/or debriefing the responses, insight was obtained on (1) the understanding and complexity of the questionnaire, (2) the time required to complete the questionnaire, (3) the theoretical validity of the results, and (4) the completeness of the attributes and level ranges used. The pilot test showed that the target groups (patients and urologists) understood the choice tasks and accurately interpreted all attributes and their levels.

Sample size. Calculation of minimum sample sizes for estimating discrete choice models from DCE data is complicated as it depends on the true values of the unknown parameters estimated in the choice models (Lancsar and Louviere, 2008). Previous studies have shown that sample sizes of 40-100 respondents may be sufficient for reliable statistical analyses (Salkeld et al, 2005; Berchi et al, 2006; de Bekker-Grob et al, 2009). We strived to reach at least these numbers of respondents.

Statistical analyses. The DCE was analysed by taking each choice among two PC treatment alternatives as an observation. Using the Nlogit software (http://www.limdep.com/), the observations were analysed by panel-mixed logit models in error component form (Train, 2003) to take into account the possibility of correlation between unobserved utilities of treatment modalities (AS, surgery, and radiotherapy), as well as the possibility of panel effects (i.e., correlation between different choices made by the same individual). More specifically, we allowed the constant for 'treatment modality' to be randomly (normally) distributed across individuals; the s.d. of the normal distribution was estimated together with the other parameters.

We selected the utility function with the best fit based on the Akaike information criterion after testing a number of different specifications for the utility (stated preference) function; for example, categorical or numerical attribute main effects, two-way interactions between attributes, several attribute transformations, and interaction between treatment modality and patients' characteristics (e.g., age, educational level, household, and having anxious/depressed feelings). As a result, the final specification of the utility function used was:

$$
\begin{aligned}
V_{\text {radiotherapy }} & =\beta_{0}+\beta_{1} \text { urine }+\beta_{2} \text { erectile }+\beta_{3} \text { radiotherapy } \times \text { anxious } \\
V_{\text {surgery }} & =\beta_{4}+\beta_{5} \text { urine }+\beta_{6} \text { erectile }+\beta_{7} \text { surgery } \times \text { anxious } \\
V_{\mathrm{AS}} & =0
\end{aligned}
$$

where

$V$ represents the observable utility (stated preference score) that a respondent has for a PC treatment scenario;

$\beta_{0}, \beta_{4}$ represent alternative specific constants for a treatment modality (AS acts as the reference level);

$\beta_{1,2}, \quad \beta_{5,6}$ represent alternative specific parameter weights (or coefficients) linearly associated with the attributes 'risk of urinary incontinence' and 'risk of erectile dysfunction';

$\beta_{3}, \beta_{7}$ represent interaction effects between patients' characteristic 'anxious/depressed feelings' and the treatment modality.

It is noteworthy that the attributes 'risk of other permanent side effects due to treatment', 'frequency of PSA testing', and 'treatment aim', all had one fixed level for each treatment modality (Table 1). Therefore, the weights associated with these attributes are captured in the alternative specific constants (i.e., $\beta_{0}$ or $\beta_{4}$ ).

In addition to the parameter estimates, the estimation procedure also allows for tests of statistical significance. The statistical significance of a coefficient $(P$-value $\leqslant 0.05)$ indicated that respondents considered the attribute important in making their choices in the DCE. The sign of the coefficient reflects whether the attribute has a positive or negative effect on the stated preference score (utility). 
We also calculated the choice probabilities for three PC treatment modalities (i.e., AS, radiotherapy with 5\% risk of permanent urinary incontinence and $25 \%$ risk of erectile dysfunction, and surgery with $20 \%$ risk of permanent urinary incontinence and $45 \%$ risk of erectile dysfunction), on the basis of the parameter estimates of patients and urologists. These treatment modalities contained the average attribute levels in the DCE. The choice probabilities were simulated based on the panel error component coefficients using 1000 draws from the probability density functions estimated for the random error components. Subsequently, these draws were used to calculate the averages of the choice probabilities.

Finally, using the extra choice set in the questionnaire (i.e., the choice set with three different treatment modalities) and the ERSPC database (i.e., data on biopsy results, the treatment advice urologists gave to the patients, and the actual choice for PC treatment), we directly compared the stated preference of each patient with their actual behaviour. For this external validity test, we only included patients diagnosed with PC who filled in the DCE and had the opportunity to choose in real life between AS, radiotherapy, and surgery (i.e., they had to make a treatment choice relevant to that presented in the survey). The external validity test was a simple straightforward test in which the stated preference of each patient (i.e., the chosen alternative from the choice set with three different treatment modalities) was directly compared with their actual behaviour (i.e., the chosen PC treatment in real life).

\section{RESULTS}

Respondents. The response rate to the questionnaire was 110 out of $150(73 \%)$ for patients and 50 out of 150 (33\%) for urologists. Patients had a mean age of 73 (s.d. $=2.2$ ) years, one-third had a higher educational level, they mainly lived together with a partner, and $21 \%$ of the patients had PC (based on the biopsy result later on; Table 2). Urologists had a mean age of 49 (s.d. $=8.3$ ) years and mainly worked in peripheral hospitals (Table 2).

Discrete choice experiment results. Of the 110 patients 97 (88\%), and of the 50 urologists $45(90 \%)$ had no difficulty filling in the DCE questionnaire. On an average, patients had a more negative attitude towards radiotherapy and surgery than that towards AS $(P<0.01$; Table 3$)$. The estimated s.d. were significant, which indicated stated preference heterogeneity among patients for PC treatment modality. Besides the treatment modality (including the one level attributes 'risk of other permanent side effects due to treatment', 'frequency of PSA testing', and 'treatment aim'), the attribute 'risk of urinary incontinence' proved to influence patients' stated preferences for PC treatment $(P<0.01$; Table 3$)$. The negative direction of this coefficient was consistent with our hypotheses and showed, therefore, theoretical validity. One patient characteristic had a significant influence on the stated preference for treatment modality: anxious/depressed feelings. The positive sign given to the interaction coefficient between patient characteristic 'anxious/depressed feelings' and treatment modality indicated that patients who had anxious/depressed feelings were more expected to opt for radiotherapy $(P=0.05)$ or surgery $(P<0.01)$ than patients who did not have anxious/depressed feelings.

On average, urologists did not have a stated preference for surgery, radiotherapy, or AS $(P>0.05$; Table 3$)$. However, the estimated s.d. for surgery was significant, which indicated stated preference heterogeneity among urologists for surgery as a PC treatment alternative. The 'risk of urine incontinence' and 'risk of erectile dysfunction' proved to influence urologists' stated preferences for PC treatment $(P<0.05$; Table 3$)$, except for the attribute 'risk of erectile dysfunction due to surgery'. The negative

\begin{tabular}{|c|c|c|}
\hline Characteristics & $\begin{array}{l}\text { Patients } \\
(n=110)\end{array}$ & $\begin{array}{l}\text { Urologists } \\
(n=50)\end{array}$ \\
\hline Age, years (mean \pm s.d.) & $72.9 \pm 2.2$ & $49.2 \pm 8.3$ \\
\hline \multicolumn{3}{|l|}{ Sex (\%) } \\
\hline $\begin{array}{l}\text { Male } \\
\text { Female }\end{array}$ & $\begin{array}{r}100 \\
0\end{array}$ & $\begin{array}{l}82 \\
18\end{array}$ \\
\hline \multicolumn{3}{|l|}{ Household (\%) } \\
\hline $\begin{array}{l}\text { Single } \\
\text { With partner }\end{array}$ & $\begin{array}{l}18 \\
82\end{array}$ & $\begin{array}{l}\text { NA } \\
\text { NA }\end{array}$ \\
\hline \multicolumn{3}{|l|}{ Educational level (\%) } \\
\hline $\begin{array}{l}\text { Low } \\
\text { Intermediate } \\
\text { High }\end{array}$ & $\begin{array}{l}31 \\
39 \\
31\end{array}$ & $\begin{array}{r}0 \\
0 \\
100\end{array}$ \\
\hline \multicolumn{3}{|c|}{ Anxious/depressed feelings (\%) } \\
\hline $\begin{array}{l}\text { Yes } \\
\text { No }\end{array}$ & $\begin{array}{r}9 \\
91\end{array}$ & $\begin{array}{l}\text { NA } \\
\text { NA }\end{array}$ \\
\hline \multicolumn{3}{|c|}{$\begin{array}{l}\text { Prostate cancer (diagnosed two weeks after filling in the } \\
\text { DCE; \%) }\end{array}$} \\
\hline $\begin{array}{l}\text { Yes } \\
\text { No }\end{array}$ & $\begin{array}{l}21 \\
79\end{array}$ & $\begin{array}{l}\text { NA } \\
\text { NA }\end{array}$ \\
\hline \multicolumn{3}{|l|}{ Hospital type (\%) } \\
\hline $\begin{array}{l}\text { University } \\
\text { Peripheral }\end{array}$ & $\begin{array}{l}\text { NA } \\
\text { NA }\end{array}$ & $\begin{array}{l}22 \\
78\end{array}$ \\
\hline Abbreviations: $\mathrm{DCE}=$ discret & $n t ; N A=n o$ & \\
\hline
\end{tabular}

coefficients of these attributes were consistent with our a priori hypotheses.

Predicted choice probabilities. The probability to choose for a specific PC treatment (i.e., AS or radiotherapy with 5\% risk of permanent urinary incontinence and $25 \%$ risk of erectile dysfunction, or surgery with $20 \%$ risk of permanent urinary incontinence and $45 \%$ risk of erectile dysfunction) showed a substantial difference between the patient groups. Patients who had anxious/ depressed feelings based on responses to the EQ-5D had a higher probability to opt for radical treatment than for AS (59\% and 41\%, respectively; Table 4). In contrast, patients who did not have anxious/depressed feelings had a lower probability to opt for radical treatment than for AS (24\% and $76 \%$, respectively), which was quite similar to the choice probabilities of urologists (23\% for radical treatment $v s 77 \%$ for AS; Table 4).

Stated preferences $v s$ real behaviour. Owing to patients' and tumour characteristics, only 10 out of 23 patients with PC (43\%) who filled in the DCE had the opportunity to choose in real life between AS, radiotherapy, and surgery (i.e., they had to make a treatment choice relevant to that presented in the survey). None of these patients mentioned anxious/depressed feelings. The urologist gave a treatment advice for 9 of these 10 patients after they filled in the DCE questions; the advice given was AS. All 10 patients stated in the DCE that they preferred AS. Indeed, 8 out of 10 chose AS, whereas one patient underwent radiotherapy, and one patient underwent surgery. 


\begin{tabular}{|c|c|c|c|c|c|}
\hline \multirow[b]{2}{*}{ Attribute levels } & & \multicolumn{2}{|c|}{ Patients } & \multicolumn{2}{|c|}{ Urologists } \\
\hline & & Coefficient & $95 \% \mathrm{Cl}$ & Coefficient & $95 \% \mathrm{Cl}$ \\
\hline \multicolumn{6}{|l|}{ Type of treatment } \\
\hline $\begin{array}{l}\text { Active surveillance (ref level) } \\
\text { Radiotherapy } \\
\text { Surgery }\end{array}$ & $\begin{array}{l}\text { Mean } \\
\text { s.d. } \\
\text { Mean } \\
\text { s.d. }\end{array}$ & $\begin{array}{r}0 \\
-5.33^{\mathrm{a}} \\
6.02^{\mathrm{a}} \\
-11.52^{\mathrm{a}} \\
10.23^{\mathrm{a}}\end{array}$ & $\begin{array}{c}(-8.55 \text { to }-2.12) \\
(3.65 \text { to } 8.38) \\
\text { (-16.97 to }-6.06) \\
\text { (5.74 to } 14.72)\end{array}$ & $\begin{array}{c}0 \\
-1.62 \\
0.64 \\
-1.41 \\
2.53^{\mathrm{a}}\end{array}$ & $\begin{array}{r}(-3.82 \text { to } 0.59) \\
(-0.85 \text { to } 2.13) \\
(-4.59 \text { to } 1.77) \\
(1.56 \text { to } 3.49)\end{array}$ \\
\hline \multicolumn{6}{|c|}{ Risk of urinary incontinence } \\
\hline $\begin{array}{l}\text { Radiotherapy (per \%) } \\
\text { Surgery (per \%) }\end{array}$ & & $\begin{array}{l}-0.18^{\mathrm{a}} \\
-0.13^{\mathrm{a}}\end{array}$ & $\begin{array}{l}(-0.32 \text { to }-0.05) \\
(-0.17 \text { to }-0.08)\end{array}$ & $\begin{array}{l}-0.21^{\mathrm{a}} \\
-0.18^{\mathrm{a}}\end{array}$ & $\begin{array}{l}(-0.33 \text { to }-0.09) \\
(-0.24 \text { to }-0.13)\end{array}$ \\
\hline \multicolumn{6}{|c|}{ Risk of erectile dysfunction } \\
\hline $\begin{array}{l}\text { Radiotherapy (per \%) } \\
\text { Surgery (per \%) }\end{array}$ & & $\begin{array}{r}0.01 \\
-0.01\end{array}$ & $\begin{array}{l}(-0.05 \text { to } 0.08) \\
(-0.04 \text { to } 0.03)\end{array}$ & $\begin{array}{c}-0.04^{b} \\
0.03\end{array}$ & $\begin{array}{l}(-0.07 \text { to } 0.00) \\
(-0.01 \text { to } 0.07)\end{array}$ \\
\hline \multicolumn{6}{|l|}{ Anxious (yes) } \\
\hline $\begin{array}{l}\text { Radiotherapy } \\
\text { Surgery }\end{array}$ & & $\begin{array}{l}5.60^{\mathrm{a}} \\
6.95^{\mathrm{a}} \\
\end{array}$ & $\begin{array}{l}\text { (1.23 to } 9.97) \\
\text { (2.48 to } 11.42 \text { ) }\end{array}$ & & NA \\
\hline
\end{tabular}

\section{Table 4. Predicted choice probabilities for prostate cancer treatment alternatives based on the stated preferences of patients and urologists}

\begin{tabular}{|c|c|c|c|}
\hline Attributes & Active surveillance & Radiotherapy & Surgery \\
\hline $\begin{array}{l}\text { Risk of permanent urinary } \\
\text { incontinency due to treatment (\%) }\end{array}$ & 0 & 5 & 20 \\
\hline $\begin{array}{l}\text { Risk of permanent erectile dysfunction } \\
\text { due to treatment }(\%)\end{array}$ & 0 & 25 & 45 \\
\hline $\begin{array}{l}\text { Risk of other permanent side effects } \\
\text { due to treatment }\end{array}$ & No & $\begin{array}{l}\text { Yes, substantial risk of bowel } \\
\text { problems and frequent urinate }\end{array}$ & $\begin{array}{l}\text { Yes, small risk of mortality within } \\
\text { six weeks }\end{array}$ \\
\hline Main aim is cure & No, the tumour remains in the body & Yes, but the disease may return & Yes, but the disease may return \\
\hline $\begin{array}{l}\text { Frequency of PSA testing with a risk of } \\
\text { new prostate biopsies }\end{array}$ & Four times a year and at least one biopsy & Once a year & Once a year \\
\hline Respondents & $\mathrm{P}(\mathrm{A})$ & $P(B)$ & $\mathrm{P}(\mathrm{C})$ \\
\hline $\begin{array}{l}\text { Patients with anxious/depressed } \\
\text { feelings }\end{array}$ & $41 \%$ & $38 \%$ & $21 \%$ \\
\hline $\begin{array}{l}\text { Patients without anxious/depressed } \\
\text { feelings }\end{array}$ & $76 \%$ & $15 \%$ & $10 \%$ \\
\hline Urologists & $77 \%$ & $13 \%$ & $11 \%$ \\
\hline
\end{tabular}

\section{DISCUSSION}

Risk of urinary incontinence was an important determinant of patients' and urologists' stated preferences for PC treatment. In addition, treatment modality (including attributes as 'frequency of PSA testing', 'treatment aim', and 'risk of other permanent side effects than urine and erectile problems') also influenced patients' stated preferences, whereas risk of erectile dysfunction due to radiotherapy mainly influenced urologists' stated preferences. Preference heterogeneity for treatment modality was substantial for both patients and urologists. Both patients and urologists had a higher choice probability for AS than that for radical treatment ( $76 \%$ vs $24 \%$, respectively and $77 \%$ vs $23 \%$, respectively), except for patients who had anxious/depressed feelings. For this latter group, the choice probability for AS was 
considerably lower than that for radical treatment (41\% vs 59\%, respectively).

There are no previous DCEs investigating patients' and urologists' stated preferences for PC treatment. However, one review study investigated why patients with localised PC choose one treatment in preference to another (Zeliadt et al, 2006); the authors found that although patients stated that side effects are important, few patients reported that side effect factors ultimately influenced their treatment choice. These results are in line with the findings in the present study, showing that urinary incontinence as a side effect had a significant influence on patients' stated preferences for PC treatment, but also the treatment modality per se (including attributes other than side effects). Our finding that patients who had anxious/depressed feelings had a higher probability to choose for radical treatment is in line with another study (van Tol-Geerdink et al, 2006), which showed that patients with higher anxiety/depressed feelings more often chose aggressive treatment than patients with low anxiety/depressed feelings. Our finding that the risk of erectile dysfunction lowered urologists' stated preference for radiotherapy but not for surgery, suggests that the urologists accept erectile dysfunction more as a consequence of surgery than that of radiotherapy. This finding deserves further research because other treatment alternatives are currently available that have a lower risk of this side effect.

Several DCE studies have shown that patients and physicians may differ substantially in their trade-offs between health-care interventions (Bishop et al, 2004; Lee et al, 2005; Mantovani et al, 2005; de Bekker-Grob et al, 2009). By understanding factors that influence patients' treatment decisions, physicians may become more sensitive to individual patients' preferences/concerns, which may have a positive effect on the process and outcomes of shared decision making. Our study makes some contributions to such understanding, on the basis of the fact that our study shows that, in contrast to urologists, risk of erectile dysfunction due to radiotherapy did not influence patients' stated preferences, whereas the treatment modality (including other side effects and non-side effects) did. Nevertheless, to obtain more insight into the trade-offs between attributes, conducting an unlabelled DCE may be worthwhile (de Bekker-Grob et al, 2010; see the following paragraph for details).

In contrast to commonly used unlabelled DCE studies in health care, we used a labelled DCE design, as PC treatments may evoke individual feelings that cannot be described in an unlabelled DCE (e.g., a patient may have a strong preference for AS because his neighbour had a positive experience with AS; or an urologist may have some additional background knowledge). Using a labelled DCE design, the PC alternatives were more realistic and can take into account individual feelings/knowledge for specific treatment modalities, which adds to the validity of the results (de Bekker-Grob et al, 2010). However, this advantage of a labelled DCE also has a disadvantage. As the PC treatment alternatives described in our choice sets were very realistic, each treatment modality had several fixed attribute levels (i.e., one fixed attribute level for 'risk of other side effects', one fixed attribute level for 'frequency of PSA testing', and one fixed attribute level for 'treatment aim'). As a consequence, the value of each of these fixed attribute levels were all captured in the alternative specific constants. Therefore, insight into which attribute of the treatment modality (i.e., risk of other side effects, frequency of PSA testing, or treatment aim) was most important for the respondents, what additional information respondents may have used in their decision for a specific alternative label, and the trade-offs respondents made between the attributes, is limited. To obtain more insight into the reasons for the preference structure of treatment modality and the alternative label, and to determine the trade-offs between these treatment-specific attributes, further research is needed.
The present study has several limitations. First, although a response rate of $33 \%$ for physicians was similar to other DCE studies (Ashcroft et al, 2006; Szeinbach et al, 2008), this response rate is clearly suboptimal. We lacked information on the experience level of the urologists in treating patients with early PC and also a complete list of reasons for non-response. It is possible that urologists who were open-minded towards treatments other than surgery were more liable to participate in our study than colleagues who were less open-minded. This might have an influence on the outcome of the study, and might explain the lower stated preference found for surgery compared with an earlier study of Ramsey et al (2011). Second, the inclusion of rates in our DCE might have caused problems with understanding the choice task; however, $88 \%$ of the patients and $90 \%$ of the urologists stated that they had no difficulty with the DCE questions. Third, we selected the most relevant attributes using literature and expert interviews; however, this careful procedure does not guarantee that attributes that we did not include are irrelevant to urologists' or patients' (stated) preferences for PC treatment. Finally, although the calculated choice probabilities based on DCE data of patients were similar to the actual behaviour in PC treatment at an aggregate level, additional insight might be obtained if reasons for differences between the stated preferences of patients and their actual behaviour in PC treatment could be investigated.

In conclusion, this study used DCE methodology to quantify the stated preferences of patients and urologists for PC treatment. Although patients and urologists generally may prefer similar treatments for PC, they showed different trade-offs between various treatment aspects. The implications are that urologists' awareness of potential differences with the patient's perspectives on treatment decisions may improve the shared decision-making process, which may avoid post-treatment decisional regret in patients.

\section{ACKNOWLEDGEMENTS}

A grant was received from the Department of Public Health, Erasmus MC-University Medical Centre Rotterdam, the Netherlands.

\section{CONFLICT OF INTEREST}

The authors declare no conflict of interest.

\section{REFERENCES}

Aning JJ, Wassersug RJ, Goldenberg SL (2012) Patient preference and the impact of decision-making aids on prostate cancer treatment choices and post-intervention regret. Curr Oncol 19: S37-S44.

Ashcroft DM, Seston E, Griffiths CE (2006) Trade-offs between the benefits and risks of drug treatment for psoriasis: a discrete choice experiment with U.K. dermatologists. Br J Dermatol 155: 1236-1241.

Berchi C, Dupuis JM, Launoy G (2006) The reasons of general practitioners for promoting colorectal cancer mass screening in France. Eur J Health Econ 7: 91-98.

Bishop AJ, Marteau TM, Armstrong D, Chitty LS, Longworth L, Buxton MJ, Berlin C (2004) Women and health care professionals' preferences for Down's syndrome screening tests: a conjoint analysis study. BJOG 111: 775-779.

Damber JE, Khatami A (2005) Surgical treatment of localized prostate cancer. Acta Oncol 44: 599-604.

de Bekker-Grob EW, Essink-Bot ML, Meerding WJ, Koes BW, Steyerberg EW (2009) Preferences of GPs and patients for preventive osteoporosis drug treatment: a discrete-choice experiment. Pharmacoeconomics 27: 211-219. 
de Bekker-Grob EW, Hol L, Donkers B, van Dam L, Habbema JD, van Leerdam ME, Kuipers EJ, Essink-Bot ML, Steyerberg EW (2010) Labeled versus unlabeled discrete choice experiments in health economics: an application to colorectal cancer screening. Value Health 13: 315-323.

de Bekker-Grob EW, Ryan M, Gerard K (2012) Discrete choice experiments in health economics: a review of the literature. Health Econ 21: 145-172.

Dolan P (1997) Modeling valuations for EuroQol health states. Med Care 35: $1095-1108$.

Emberton M (2010) Medical treatment of benign prostatic hyperplasia: physician and patient preferences and satisfaction. Int J Clin Pract 64: $1425-1435$.

Gillitzer R, Thuroff JW (2003) Technical advances in radical retropubic prostatectomy techniques for avoiding complications. Part II: vesico-urethral anastomosis and nerve-sparing prostatectomy. BJU Int 92: $178-184$.

Hall J, Fiebig DG, King MT, Hossain I, Louviere JJ (2006) What influences participation in genetic carrier testing? Results from a discrete choice experiment. J Health Econ 25: 520-537.

Hensher DA, Rose JM, Greene WH (2005) Applied choice analysis: a primer. Cambridge University Press: Cambridge, UK.

Kim SI, Kang JY, Lee HW, Seong do H, Cho JS (2011) A survey conducted on patients' and urologists' perceptions of benign prostatic hyperplasia. Urol Int 86: 278-283.

Klotz L (2006) Active surveillance versus radical treatment for favorable-risk localized prostate cancer. Curr Treat Options Oncol 7: 355-362.

Korfage IJ, Essink-Bot ML, Borsboom GJ, Madalinska JB, Kirkels WJ, Habbema JD, Schroder FH, de Koning HJ (2005) Five-year follow-up of health-related quality of life after primary treatment of localized prostate cancer. Int J Cancer 116: 291-296.

Lancsar E, Louviere J (2008) Conducting discrete choice experiments to inform healthcare decision making: a user's guide. Pharmacoeconomics 26: 661-677.

Lee A, Gin T, Lau AS, Ng FF (2005) A comparison of patients' and health care professionals' preferences for symptoms during immediate postoperative recovery and the management of postoperative nausea and vomiting. Anesth Analg 100: 87-93.

Mantovani LG, Monzini MS, Mannucci PM, Scalone L, Villa M, Gringeri A (2005) Differences between patients', physicians' and pharmacists' preferences for treatment products in haemophilia: a discrete choice experiment. Haemophilia 11: 589-597.

Montgomery AA, Fahey T (2001) How do patients' treatment preferences compare with those of clinicians? Qual Health Care 10(Suppl 1): i39-i43.

Pearmain D, Swanson J, Kroes E, Bradley M (1991) Stated Preferences Techniques: A Guide To Practice. The Hague, Steer Davis Gleave and Hague Consulting Group: Hagues, The Netherlands.

Penson DF, McLerran D, Feng Z, Li L, Albertsen PC, Gilliland FD, Hamilton A, Hoffman RM, Stephenson RA, Potosky AL, Stanford JL (2008) 5-year urinary and sexual outcomes after radical prostatectomy: results from the Prostate Cancer Outcomes Study. J Urol 179: S40-S44.

Potosky AL, Davis WW, Hoffman RM, Stanford JL, Stephenson RA, Penson DF, Harlan LC (2004) Five-year outcomes after prostatectomy or radiotherapy for prostate cancer: the prostate cancer outcomes study. J Natl Cancer Inst 96: 1358-1367.

Ramsey SD, Zeliadt SB, Fedorenko CR, Blough DK, Moinpour CM, Hall IJ, Smith JL, Ekwueme DU, Fairweather ME, Thompson IM, Keane TE, Penson DF (2011) Patient preferences and urologist recommendations among local-stage prostate cancer patients who present for initial consultation and second opinions. World J Urol 29: 3-9.
Reed Johnson F, Lancsar E, Marshall D, Kilambi V, Muhlbacher A, Regier DA, Bresnahan BW, Kanninen B, Bridges JF (2013) Constructing experimental designs for discrete-choice experiments: report of the ISPOR Conjoint Analysis Experimental Design Good Research Practices Task Force. Value Health 16: 3-13.

Roobol MJ, Schroder FH (2003) European Randomized Study of Screening for Prostate Cancer: achievements and presentation. BJU Int 92(Suppl 2): $117-122$.

Ryan M (2004) Discrete choice experiments in health care. BMJ 328: 360-361. Salkeld G, Solomon M, Butow P, Short L (2005) Discrete-choice experiment to measure patient preferences for the surgical management of colorectal cancer. Br J Surg 92: 742-747.

Schroder FH, Hugosson J, Roobol MJ, Tammela TL, Ciatto S, Nelen V, Kwiatkowski M, Lujan M, Lilja H, Zappa M, Denis LJ, Recker F, Berenguer A, Maattanen L, Bangma CH, Aus G, Villers A, Rebillard X, van der Kwast T, Blijenberg BG, Moss SM, de Koning HJ, Auvinen A (2009) Screening and prostate-cancer mortality in a randomized European study. $N$ Engl J Med 360: $1320-1328$.

Schroder FH, Hugosson J, Roobol MJ, Tammela TL, Ciatto S, Nelen V, Kwiatkowski M, Lujan M, Lilja H, Zappa M, Denis LJ, Recker F, Paez A, Maattanen L, Bangma CH, Aus G, Carlsson S, Villers A, Rebillard X, van der Kwast T, Kujala PM, Blijenberg BG, Stenman UH, Huber A, Taari K, Hakama M, Moss SM, de Koning HJ, Auvinen A (2012) Prostate-cancer mortality at 11 years of follow-up. N Engl J Med 366: 981-990.

Stanford JL, Feng Z, Hamilton AS, Gilliland FD, Stephenson RA, Eley JW, Albertsen PC, Harlan LC, Potosky AL (2000) Urinary and sexual function after radical prostatectomy for clinically localized prostate cancer: the Prostate Cancer Outcomes Study. JAMA 283: 354-360.

Street DJ, Burgess L, Louviere JJ (2005) Constructing optimal and nearly optimal stated choice experiments. Intern J Res Marketing 22: 459-470.

Swait J, Louviere J (1993) The role of the scale parameter in the estimation and comparison of multinomial logit models. J Marketing Res 30: 305-314.

Szeinbach SL, Harpe SE, Williams PB, Elhefni H (2008) Testing for allergic disease: parameters considered and test value. BMC Fam Pract 9: 47.

Train KE (2003) Discrete Choice Methods With Simulations. Cambridge University Press: Cambridge, UK.

van den Bergh RC, Essink-Bot ML, Roobol MJ, Schroder FH, Bangma CH, Steyerberg EW (2010) Do anxiety and distress increase during active surveillance for low risk prostate cancer? J Urol 183: 1786-1791.

van Tol-Geerdink JJ, Stalmeier PF, van Lin EN, Schimmel EC, Huizenga H, van Daal WA, Leer JW (2006) Do patients with localized prostate cancer treatment really want more aggressive treatment? J Clin Oncol 24: 4581-4586.

van Tol-Geerdink JJ, Willem Leer J, Weijerman PC, van Oort IM, Vergunst H, van Lin EN, Alfred Witjes J, Stalmeier PF (2013) Choice between prostatectomy and radiotherapy when men are eligible for both: a randomized controlled trial of usual care vs decision aid. BJU Int 111: 564-573.

Zeliadt SB, Ramsey SD, Penson DF, Hall IJ, Ekwueme DU, Stroud L, Lee JW (2006) Why do men choose one treatment over another?: a review of patient decision making for localized prostate cancer. Cancer 106: 1865-1874.

This work is published under the standard license to publish agreement. After 12 months the work will become freely available and the license terms will switch to a Creative Commons AttributionNonCommercial-Share Alike 3.0 Unported License. 


\section{APPENDIX 1}

Two examples of choice sets

Assume that both treatments for prostate cancer treatment are equally effective regarding survival rate. Which treatment do you prefer? (Please tick one box.)

\begin{tabular}{|c|c|c|}
\hline & Radiotherapy & Active surveillance \\
\hline $\begin{array}{l}\text { Risk of permanent } \\
\text { urinary incontinence } \\
\text { due to treatment }\end{array}$ & 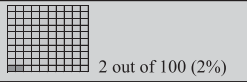 & 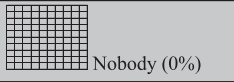 \\
\hline $\begin{array}{l}\text { Risk of permanent } \\
\text { erectile dysfunction } \\
\text { due to treatment }\end{array}$ & 每 35 out of $100(35 \%)$ & 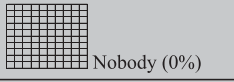 \\
\hline $\begin{array}{l}\text { Risk of other } \\
\text { permanent side-effects } \\
\text { due to treatment }\end{array}$ & $\begin{array}{l}\text { Yes, substantial risk of } \\
\text { - Bowel problems } \\
\text { - Frequent urge to urinate }\end{array}$ & No \\
\hline Main aim is cure & $\begin{array}{l}\text { Yes, but the disease } \\
\text { may return }\end{array}$ & $\begin{array}{l}\text { No, the tumour remains } \\
\text { in the body }\end{array}$ \\
\hline $\begin{array}{l}\text { Frequency of PSA testing with } \\
\text { a risk of new prostate biopsies }\end{array}$ & Once in a year & $\begin{array}{l}\text { Four times in a year and at } \\
\text { least one biopsy per year }\end{array}$ \\
\hline $\begin{array}{l}\text { Which alternative do you } \\
\text { prefer? }\end{array}$ & & \\
\hline
\end{tabular}

Assume that both treatments for prostate cancer treatment are equally effective regarding survival rate. Which treatment do you prefer? (Please tick one box.)

\begin{tabular}{|c|c|c|}
\hline & Surgery & Surgery \\
\hline $\begin{array}{l}\text { Risk of permanent } \\
\text { urinary incontinence } \\
\text { due to treatment }\end{array}$ & \#\#期 20 out of $100(20 \%)$ & \#\# \\
\hline $\begin{array}{l}\text { Risk of permanent } \\
\text { erectile dysfunction } \\
\text { due to treatment }\end{array}$ & \begin{tabular}{|l|l|}
+8 \\
\end{tabular} & 55 out of $100(55 \%)$ \\
\hline $\begin{array}{l}\text { Risk of other } \\
\text { permanent side-effects } \\
\text { due to treatment }\end{array}$ & $\begin{array}{l}\text { Yes, small risk of } \\
\text { - Mortality within } 6 \text { weeks }\end{array}$ & $\begin{array}{l}\text { Yes, small risk of } \\
\text { - Mortality within } 6 \text { weeks }\end{array}$ \\
\hline Main aim is cure & $\begin{array}{l}\text { Yes, but the disease } \\
\text { may return }\end{array}$ & $\begin{array}{l}\text { Yes, but the disease } \\
\text { may return }\end{array}$ \\
\hline $\begin{array}{l}\text { Frequency of PSA testing with } \\
\text { a risk of new prostate biopsies }\end{array}$ & Once in a year & Once in a year \\
\hline $\begin{array}{l}\text { Which alternative do you } \\
\text { prefer? }\end{array}$ & & \\
\hline
\end{tabular}

\section{APPENDIX II}

A choice set presenting the most plausible attribute levels for three prostate cancer treatment alternatives

\begin{tabular}{|c|c|c|c|}
\hline & Active Surveillance & Radiotherapy & Surgery \\
\hline $\begin{array}{l}\text { Risk of permanent } \\
\text { urinary incontinence } \\
\text { due to treatment }\end{array}$ & $\begin{array}{l}\#^{2} \\
\text { Nobody }(0 \%) \\
\end{array}$ & 5 out of $100(5 \%)$ & 20 out of 100 (20\%) \\
\hline $\begin{array}{l}\text { Risk of permanent } \\
\text { erectile dysfunction } \\
\text { due to treatment }\end{array}$ & 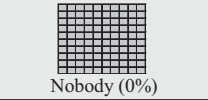 & 25 out of $100(25 \%)$ & 45 out of $100(45 \%)$ \\
\hline $\begin{array}{l}\text { Risk of other } \\
\text { permanent side-effects } \\
\text { due to treatment }\end{array}$ & No & $\begin{array}{c}\text { Yes, substantial risk of } \\
\text { - Bowel problems } \\
\text { - } \begin{array}{c}\text { Frequent urge to } \\
\text { urinate }\end{array}\end{array}$ & $\begin{array}{c}\text { Yes, small risk of } \\
\text { mortality within } 6 \\
\text { weeks }\end{array}$ \\
\hline Main aim is cure & $\begin{array}{l}\text { No, the tumour remains } \\
\text { in the body }\end{array}$ & $\begin{array}{l}\text { Yes, but the disease } \\
\text { may return }\end{array}$ & $\begin{array}{l}\text { Yes, but the disease } \\
\text { may return }\end{array}$ \\
\hline $\begin{array}{l}\text { Frequency of PSA } \\
\text { testing with a risk of } \\
\text { new prostate biopsies }\end{array}$ & $\begin{array}{c}\text { Four times in a year and } \\
\text { at least one biopsy per } \\
\text { year }\end{array}$ & Once in a year & Once in a year \\
\hline $\begin{array}{l}\text { Which alternative do } \\
\text { you prefer? }\end{array}$ & & & \\
\hline
\end{tabular}

